\title{
A Case of IgG4-Related Bilateral Palpebral Conjunctivitis
}

\author{
Toshiya Nagai Tatsuya Yunoki Atsushi Hayashi \\ Department of Ophthalmology, Graduate School of Medicine and Pharmaceutical \\ Sciences, University of Toyama, Toyama, Japan
}

\section{Keywords}

IgG4-related ocular disease $\cdot$ Hypertrophic ectropion · Palpebral conjunctivitis

\begin{abstract}
The most common sites of IgG4-related ocular disease are the lacrimal glands, infraorbital nerve, and extraocular muscles. Other ocular adnexal sites are relatively rare. We report a rare case of an 83-year-old man who developed palpebral conjunctivitis following bilateral hypertrophic ectropion of the eyelid. Tissue immunostaining revealed many lgG4-positive plasma cells (67 lgG4/74 lgG cells/high-power field). The serum IgG4 level was $76.9 \mathrm{mg} / \mathrm{dL}$, which was within the normal range. The diagnosis was probable IgG4-related disease. The possibility of IgG4-related disease should be considered in a patient presenting with refractory conjunctivitis and hyperemia or hypertrophy of the lower eyelid.

(C) 2019 The Author(s) Published by S. Karger AG, Basel
\end{abstract}

\section{Introduction}

IgG4-related disease (IgG4-RD) is a lymphoproliferative disorder, the hallmark of which is an elevated level of IgG4-positive plasma cells. IgG4-RD lesions occur in various organs, including the salivary glands, lymph nodes, retroperitoneum, lungs, and pancreas [1-3]. In ophthalmology, commonly reported sites are the lacrimal glands, extraocular muscles, trigeminal nerve, and orbital soft tissue [4,5]. There have also been occasional reports of IgG4-RD developing at various sites around the eyes, including the eyelid $[5,6]$, conjunctiva $[7,8]$, and 


\section{Case Reports in Ophthalmology}

lacrimal sac [9]. In this report, we describe a case of IgG4-RD with palpebral conjunctivitis following bilateral hypertrophic ectropion of the lower eyelid.

\section{Case Report}

The patient is an 83-year-old Japanese man who presented with persistent conjunctival hyperemia in both eyes. He had been treated with a topical steroid for 1 month and followed up at a local ophthalmology clinic. When there was no improvement, he was referred to our hospital. On examination, his best-corrected decimal visual acuity was 1.2 in both eyes. Slitlamp microscopy revealed hyperemia of the palpebral conjunctiva and hypertrophic ectropion of the eyelid (Fig. 1). Anterior and posterior chamber were normal except of mild cataract. No abnormality was detected on fundoscopy. We performed a biopsy of the palpebral conjunctiva bilaterally to exclude malignant neoplastic disease. Microscopic examination showed a dense infiltration of plasma cells under the conjunctival epithelium on both sides (Fig. 2a, b). No fibrosis was detected. There was no difference in the numbers of kappa-positive or lambda-positive cells and no findings on in situ hybridization suggestive of malignant lymphoma. Many IgG4-positive plasma cells were observed on tissue immunostaining (67 IgG4/74 IgG cells per high-power field; Fig. 2c). The patient's IgG4 serum level was 76.9 $\mathrm{mg} / \mathrm{dL}$, which was within the normal range. Magnetic resonance imaging showed no enlargement of the lacrimal glands, infraorbital nerve, or extraocular muscles or any significant swelling of the cervical lymph nodes. A full-body computed tomography scan found no signs of other organ involvement.

The patient refused systemic steroid therapy and was followed up without treatment. A biopsy after 6 months of follow-up showed no deterioration of the palpebral conjunctiva (Fig. $3)$.

\section{Discussion}

The diagnostic criteria for IgG4-RD are including the following: (1) clinical examination shows characteristic diffuse/localized swelling or masses in single or multiple organs; (2) hematologic examination shows an elevated serum IgG4 concentration ( $\geq 135 \mathrm{mg} / \mathrm{dL})$; and (3) histopathologic examination shows marked lymphocyte and plasmacyte infiltration and fibrosis with infiltration of IgG4-positive plasma cells (an lgG4-positive/IgG-positive cell ratio $>40 \%$ and $>10$ IgG4-positive plasma cells per high-power field) [10]. Meeting of criteria 1, 2, and 3 indicates definite IgG4-RD, 1 and 3 probable IgG4-RD, and 1 and 2 possible IgG4-RD [10]. Our patient had hypertrophic enlargement of the palpebral conjunctiva bilaterally, and pathologic examination revealed proliferation of IgG4-positive plasma cells (an lgG4-positive/IgG-positive cell ratio of $90.5 \%$ and 67 IgG4-positive plasma cells per high-power field). Therefore, criteria 1 and 3 were met, indicating a diagnosis of probable IgG4-RD. However, the patient did not have the fibrosis often seen in IgG4-RD or an elevated serum IgG4 level, so will be followed up closely.

There have been occasional reports of IgG4-related ocular disease in the conjunctiva, eyelids, and lacrimal sac [5-9] but none on IgG4-related palpebral conjunctivitis with bilateral hypertrophic ectropion of the eyelid. It is thought that IgG4-RD presenting such condition is very rare. In addition, serum IgG4 was normal in this case. There are past reports that serum IgG4 was normal in atypical presentation of IgG4-RD [6, 7]. It seems that we should consider 
any other inflammatory conditions that can mimic atypical condition of IgG4-RD, such as palpebral conjunctivitis.

IgG4-RD is a systemic disease that is reportedly associated with a high risk of malignancy [11-13]. Therefore, definitive diagnosis and systemic examination are important. The possibility of IgG4-RD should be considered in a patient who presents with refractory conjunctivitis and hyperemia or hypertrophy of the eyelid.

\section{Acknowledgments}

The authors thank Dr. Noriko Okuno, University of Toyama, for her pathological diagnosis.

\section{Statement of Ethics}

The patient provided informed consent for his case to be published.

\section{Disclosure Statement}

The authors declare that they have no conflicts of interest.

\section{Author Contributions}

T.Y. and T.N. drafted the manuscript and collected the data. T.Y. and A.H. reviewed the final version of the manuscript. All authors have read and approved the final manuscript.

\section{References}

1 Hamano H, Kawa S, Ochi Y, Unno H, Shiba N, Wajiki M, et al. Hydronephrosis associated with retroperitoneal fibrosis and sclerosing pancreatitis. Lancet. 2002 Apr;359(9315):1403-4.

2 Umehara H, Okazaki K, Masaki Y, Kawano M, Yamamoto M, Saeki T, et al. Comprehensive diagnostic criteria for IgG4-related disease (IgG4-RD), 2011. Mod Rheumatol. 2012 Feb;22(1):21-30.

3 Zen Y, Nakanuma Y. IgG4-related disease: a cross-sectional study of 114 cases. Am J Surg Pathol. 2010 Dec;34(12):1812-9.

4 Wallace ZS, Khosroshahi A, Jakobiec FA, Deshpande V, Hatton MP, Ritter J, et al. IgG4-related systemic disease as a cause of "idiopathic" orbital inflammation, including orbital myositis, and trigeminal nerve involvement. Surv Ophthalmol. 2012 Jan-Feb;57(1):26-33.

5 Sogabe Y, Ohshima K, Azumi A, Takahira M, Kase S, Tsuji H, et al. Location and frequency of lesions in patients with IgG4-related ophthalmic diseases. Graefes Arch Clin Exp Ophthalmol. 2014 Mar;252(3):531-8.

6 Leivo T, Koskenmies S, Uusitalo M, Tynninen O. IgG4-related disease mimicking chalazion in the upper eyelid with skin manifestations on the trunk. Int Ophthalmol. 2015 Aug;35(4):595-7.

7 da Fonseca FL, Ramos RI, de Lima PP, Nogueira AB, Matayoshi S. Unilateral eyelid mass as an unusual presentation of ocular adnexal IgG4-related inflammation. Cornea. 2013 Apr;32(4):517-9.

8 Philippakis E, Cassoux N, Charlotte F, LeHoang P, Bodaghi B, Bloch-Queyrat C, et al. IgG4-related disease masquerading as recurrent scleritis and chronic conjunctivitis. Ocul Immunol Inflamm. 2015 Apr;23(2):16872.

9 Takahashi Y, Takahashi E, Nishimura K, Kakizaki H. Immunoglobulin G4-related dacryocystitis. Can J Ophthalmol. 2017 Oct;52(5):e188-90.

10 Goto H, Takahira M, Azumi A; Japanese Study Group for IgG4-Related Ophthalmic Disease. Diagnostic criteria for IgG4-related ophthalmic disease. Jpn J Ophthalmol. 2015 Jan;59(1):1-7. 


\section{Case Reports in Ophthalmology}

11 Yamamoto M, Takahashi H, Tabeya T, Suzuki C, Naishiro Y, Ishigami K, et al. Risk of malignancies in IgG4related disease. Mod Rheumatol. 2012 Jun;22(3):414-8.

12 Gill J, Angelo N, Yeong ML, McIvor N. Salivary duct carcinoma arising in IgG4-related autoimmune disease of the parotid gland. Hum Pathol. 2009 Jun;40(6):881-6.

13 Kubota T, Moritani S, Yoshino T, Nagai H, Terasaki H. Ocular adnexal marginal zone B cell lymphoma infiltrated by IgG4-positive plasma cells. J Clin Pathol. 2010 Dec;63(12):1059-65.
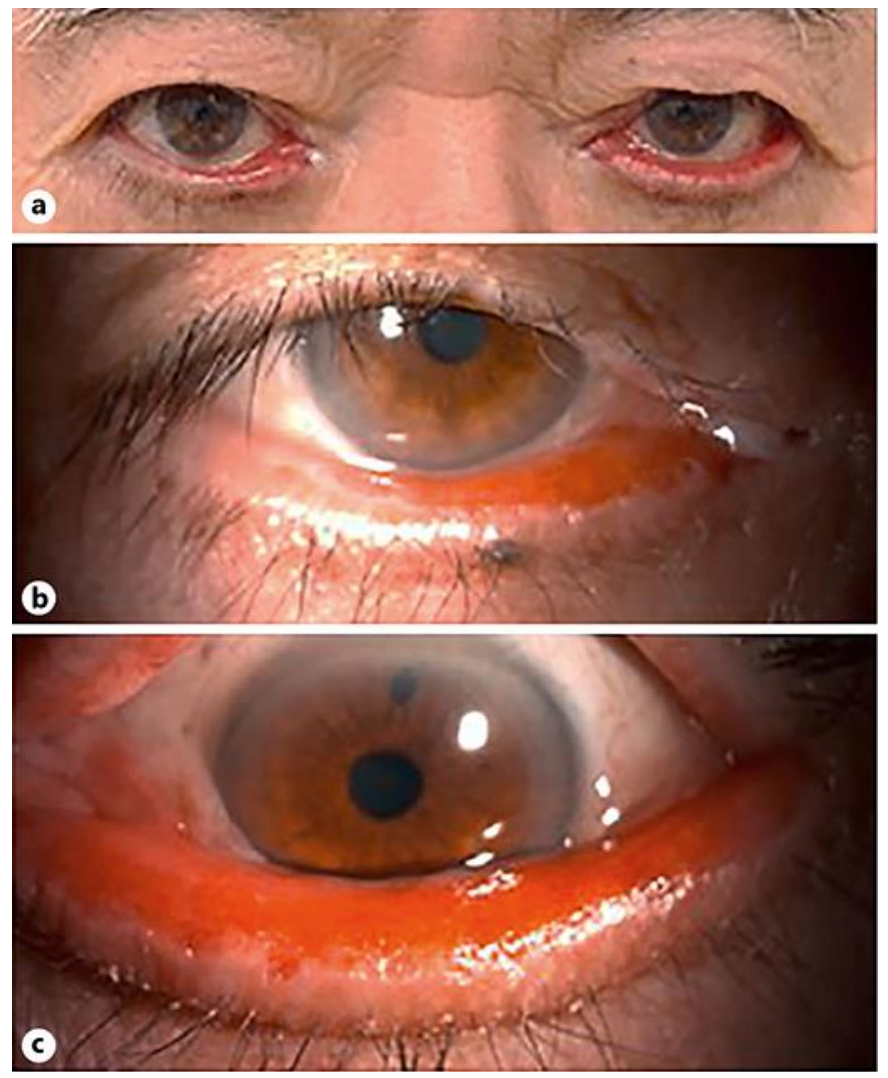

Fig. 1. Palpebral conjunctivitis with bilateral hypertrophic ectropion of the eyelid. a A photograph of the face. b A slit-lamp photograph showing the conjunctival findings in the right eye. c A slit-lamp photograph showing the conjunctival findings in the left eye. 


\section{Case Reports in Ophthalmology}

Case Rep Ophthalmol 2019;10:299-303

๑ 2019 The Author(s). Published by S. Karger AG, Basel www.karger.com/cop

Nagai et al.: IgG4-Related Bilateral Palpebral Conjunctivitis
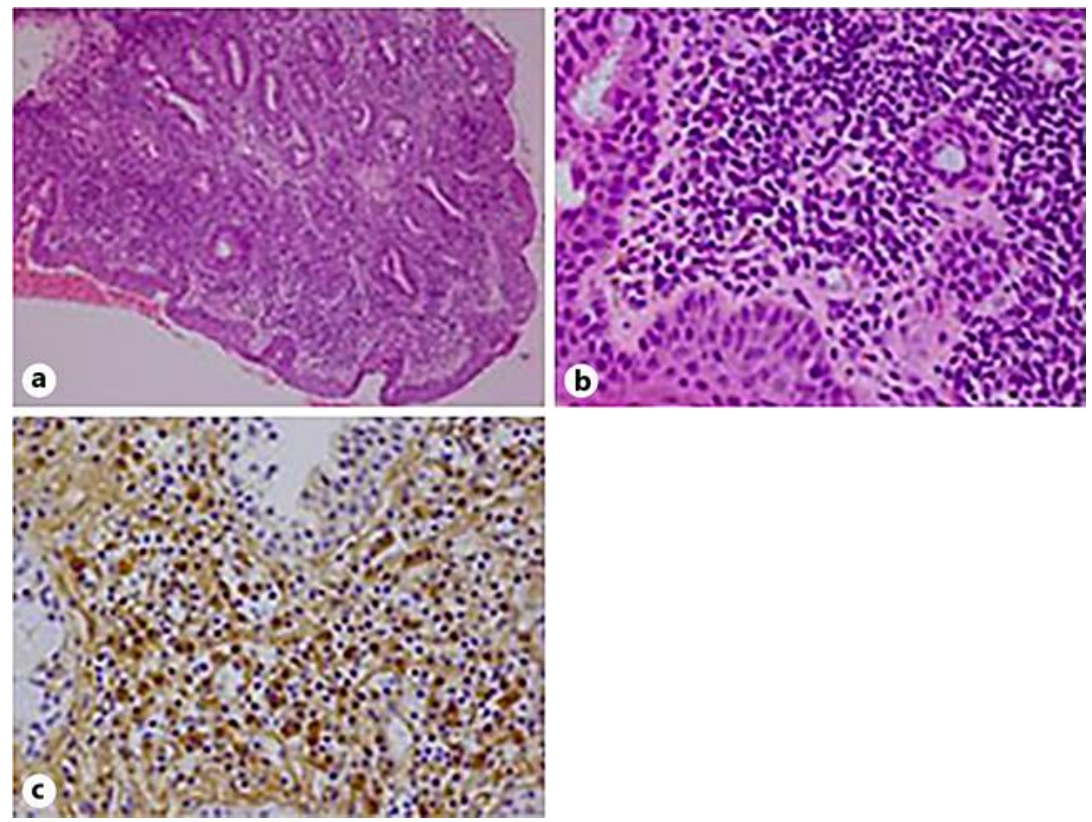

Fig. 2. Histopathological analysis showing a dense infiltration of plasma cells (a, original magnification $\times 40$; b, original magnification $\times 400$ ). c Tissue immunostaining of the conjunctival biopsy showing many IgG4positive plasma cells (original magnification $\times 400$ ).

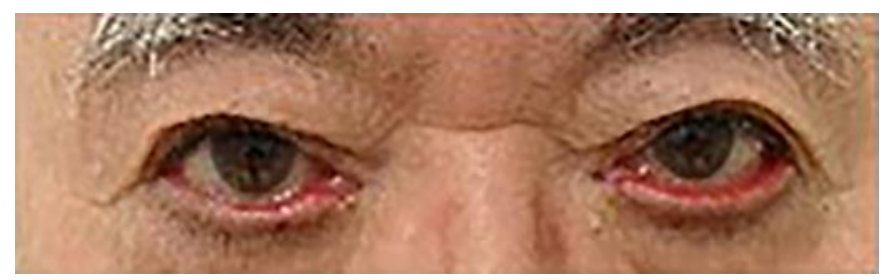

Fig. 3. A photograph after 6 months of follow-up. 